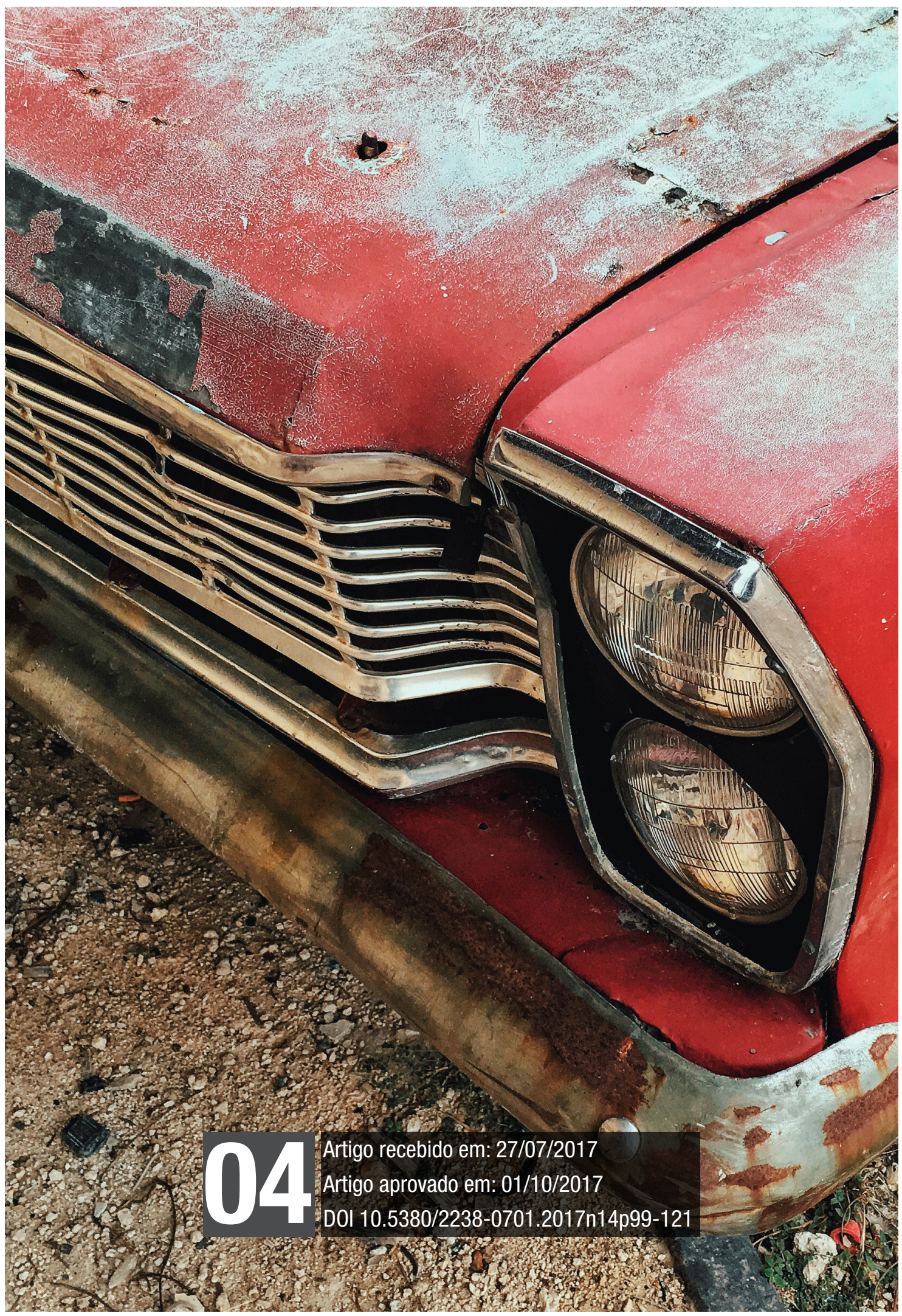


Gênero. Singularidades masculinas. Masculinidade hegemônica. 


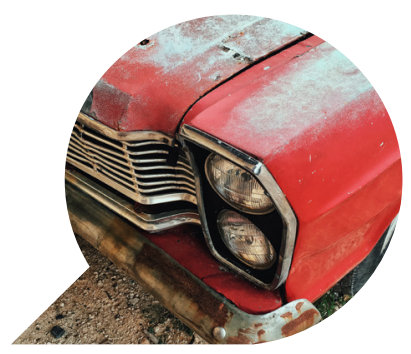

\title{
Consumo e gênero: revisitando as singularidades masculinas nas comunicações publicitárias
}

\author{
Consumption and Gender: \\ revisiting male singularities in advertising
}

Consumo y Género: revisando las singularidades masculinas en las comunicaciones publicitarias

\section{FÁBIO CAIM}

Resumo: O presente artigo versa sobre a questão das singularidades do masculino na linguagem publicitária, colocando em discussão o que se compreende como gênero e, consequentemente, a própria masculinidade hegemônica. Inicialmente, abordam-se questões teóricas sobre gênero desde a perspectiva sociológica e antropológica, para em seguida abrir espaço para as abordagens psicanalíticas. A visão que permeia todos esses campos de conhecimento é aquela fornecida pela semiótica, que parte do pressuposto de que o acesso ao real só é feito via signos, portanto, sempre mediado por algo aquém da capacidade sensória do sujeito. O segundo movimento deste trabalho coloca em pauta algumas comunicações publicitárias, bem como garotos-propaganda criados a partir da década de 70 e que deram espaço para contestações

\footnotetext{
* Doutor em Comunicação e Semiótica (PUC/SP). Professor universitário nos cursos de Publicidade
} e Propaganda da Faculdade Cásper Líbero e da Facamp. E-mail: fabiocaim@uol.com.br 
contemporâneas mais pertinentes e explícitas, como o vídeo-manifesto da marca Natura Homem, que coloca em xeque o gênero masculino hegemônico.

Palavras-chave: Gênero; Singularidades masculinas; Masculinidade hegemônica; Natura Homem.

Abstract: This article deals with the question of the male singularities in the advertising language bringing to discussion what we understand about gender and, consequently, the hegemonic masculinity itself. Initially, theoretical questions about gender are approached from the sociological and anthropological perspective and then open space for psychoanalytics approaches. The view that permeates all those fields of knowledge is provided by semiotics which assumes that access to the real is only done by signs, therefore, always mediated by something beyond the sensory capacity of the individual. The second movement of this paper sets in motion some advertising communications as well as advertising characters created from the 70's and that gave space for more pertinent and explicit contemporary contestations such as the video manifesto of the Natura Homem which contest the hegemonic masculine gender.

Key-words: Gender; Male singularities; Hegemonic masculinity; Natura Homem.

Resumen: El artículo pone en cuestión las singularidades del masculino en el lenguaje publicitario, trabajando desde lo que se alcanza como género $y$, consecuentemente, la masculinidad hegemónica. De hecho, se abordan cuestiones teóricas sobre el género desde la perspectiva sociológica y antropológica, para luego abrir espacio para abordajes psicoanalíticos. La visión que impregna todos estos rincones de conocimiento es la proporcionada por la semiótica partiendo del principio que el acceso al real sólo se hace por signos, por lo tanto, siempre mediado por algo más allá de la capacidad sensorial del sujeto. El segundo movimiento de este trabajo pone en pauta algunas comunicaciones publicitarias, así como chicos de la publicidad creados a partir de la década de los 70 y que dieron espacio para contestaciones contemporáneas más pertinentes y explícitas, como el vídeo manifiesto de la marca Natura Homem, que pone en xeque o género masculino hegemónico. 


\section{Introdução}

Não é novidade a relação entre consumo e gênero na história da comunicação publicitária brasileira (RAMOS, 1985 e SIMÕES, 2006). Desde seu início, com o primeiro anúncio sendo publicado em 1808 na Gazeta do Rio de Janeiro divulgando a venda de imóveis - "Quem quiser comprar uma morada de casas de sobrado, com frente para Santa Rita, fale com Ana Joaquina da Silva, que mora nas mesmas casas, ou com o Capitão Francisco Pereira de Mesquita, que tem ordem para as vender" (RAMOS, 1985, p 9) - a relação entre esses dois campos sempre foi simbiótica. "Ana Joaquina da Silva” é a pessoa que deve ser procurada, no entanto, para resolver e tomar a decisão quem deve ser consultado é o "Capitão Francisco Pereira de Mesquista".

As divisões estão implícitas no anúncio, até porque o qualificativo "Capitão" ainda confere ar diferenciado e de maior autoridade ao sujeito masculino, já que é dele a "ordem para as vender".

Para além da linguagem publicitária, as divisões de gênero orientaram segmentações de mercado. Por exemplo, existem carros focados no consumidor jovem, nas mulheres, nos homens, em homens com mais de 50, assim como existem canetas pensadas para gêneros diferentes (a marca Bic tem uma linha específica para mulheres que com muita obviedade faz uso da cor rosa na sua estética), além de outras tantas marcas e produtos que usam esse eixo como organizador e orientador de suas comunicações.

Para além dos recortes puramente demográficos como faixa etária, classe social, estado civil, sexo entre outros o ambiente de consumo é o campo de articulação de uma evidente apropriação do gênero como elemento de segmentação e exploração de mercado.

De maneira bastante generalizada, os mercados são divididos em homens e mulheres recortados por sua classe social e faixa etária, como forma de definir focos para as comunicações de consumo. Todavia, há sim um movimento em ascensão na atividade de marketing e publicidade de construção desse personagem (ou persona como atualmente é designado no campo publicitário), que é foco das comunicações, baseado no seu estilo de vida, denotando assim uma compreensão mais ampla sobre as diferenças existentes nas performances sociais dos sujeitos.

Pesquisas conhecidas com esse teor são o VALS - Values and Life Style (GIL, CAMPOMAR, 2006) originariamente desenvolvida para o mercado norte-americano, mas que atualmente é usada em outros paí- 
ses e faz um inventário de alguns tipos de estilos de vida. No Brasil, o Serasa Experian tem uma pesquisa ampla chamada Mosaic que define 11 grupos de estilos de vida, com algumas segmentações em cada um.

Via de regra, o gênero que aparece nas comunicações publicitárias (com algumas exceções que serão discutidas posteriormente) apenas alicerça e apoia os estereótipos calcados na perspectiva binária de oposição entre homem e mulher, como se o produto destinado a um não pudesse ser consumido pelo outro com o objetivo de que os legissignos simbólicos, regras e crenças culturais, não sejam ultrapassados e postos à prova impactando as formas de se relacionar e consumir na sociedade.

Os gêneros estereotipados são tão fortemente enraizados na cultura que se um sujeito masculino usar uma caneta rosa pode significar, para os seus pares, que sua masculinidade é "falsa", como se o qualissigno cor rosa -, por meio de sua réplica na caneta estabelecesse uma quebra no vínculo simbólico do sujeito com todo o sistema patriarcal, que lhe dita regras de conduta, portanto, do que é ser masculino.

Tais regras ancoram o masculino em um determinado sistema que, por sua vez, o enraíza no biológico - ou seja, ser masculino deve significar ser macho.

Os estudos de gênero privilegiam a dimensão de escolha cultural pretendendo descartar as alusões a um ativismo biológico para explicar as feições que o feminino e o masculino assumem em múltiplas culturas (HEILBORN, 2004 apud SAMPAIO e GARCIA, 2010, p. 84).

E

Os estudos sobre gênero partem, portanto, do pressuposto de que a contribuição da biologia é insuficiente para a compreensão das diferenças subjetivas existentes entre homens e mulheres (SORJ, 1902) e se apoiam num argumento construtivista para fundamentar suas conclusões. (SAMPAIO e GARCIA, 2010, p. 84).

Portanto, a condição de gênero, exposta nas citações acima, diz respeito aos invólucros sócio culturais adquiridos em função do ambiente de imersão no qual o sujeito se encontra, ambiente este que age sobre ele e que, em certa medida, é impactado pelas múltiplas manifestações que o antecedem.

Se aceitamos que gênero é construído e que não está, sob nenhuma forma, "natural" ou inevitavelmente preso ao sexo, então a distinção 
entre sexo e gênero parecerá cada vez mais instável. Assim, o gênero é radicalmente independente do sexo. Ele é "um artifício à deriva", como diz Butler (GT, p. 6) ${ }^{1}$, argumentando que, se o "sexo" é tão culturalmente construído quanto o gênero, de maneira que a distinção sexo/ gênero não é na verdade distinção alguma (GT, p. 7). Butler descarta a ideia de que o gênero ou o sexo seja uma "substância permanente", argumentando que uma cultura heterossexual e heterossexista estabelece a coerência dessas categorias para perpetuas e manter o que a poeta e crítica feminista Adrienne Rich chamou de "heterossexualidade compulsória" - a ordem dominante pela qual os homens e as mulheres se veem solicitados ou forçados a ser heterossexuais (SALIH, 2013, p. 71).

Novamente, resgatamos a assertiva que sexo e gênero são categorias diferentes, que segundo Butler sequer existiriam como independentes, pois que o sexo sempre foi gênero, já que o sujeito só se fez e faz por estar imerso na cultura.

No entanto, é evidente que não é possível pensar o gênero apenas a partir de uma perspectiva sociológica, ou mesmo antropológica; é mais que necessário imiscuir tais campos com o da psicanálise, visto que estamos falando, também, de uma constituição psíquica.

Em $O$ e u e o id, ele discorre sobre o luto como estrutura incipiente de formação do eu, tese cujos rastos podem ser encontrados no ensaio de 1917, Luto e melancolia. Na experiência de perder um ser humano amado, argumenta Freud, o eu incorpora esse outro em sua própria estrutura, assumindo atributos do outro e "preservando-o" por meio de atos mágicos de imitação. A perda do outro desejado e amado é superada mediante um ato específico de identificação, ato esse que busca acolher o outro na própria estrutura do eu: "Assim, refugiando-se no eu, o amor escapa à aniquilação" (p. 178). Essa identificação não é meramente momentânea ou ocasional, mas se torna uma nova estrutura da identidade; com efeito, o outro se torna parte do eu através da internalização permanente de seus atributos (BUTLER, 2017, p. 107).

Enquanto, segundo a perspectiva sociológica compreendemos que o sujeito acessa diversas possibilidades de gênero no fértil campo da cultura; da visão psicanalítica apreendemos que há uma tendência que o amor pelo outro seja internalizado mediante traços psíquicos para que a identificação se perpetue, isto é, para que o amor não se perca.

\footnotetext{
${ }^{1}$ A autora citada se refere ao famoso livro de Judith Butler - Gender Trouble: Seminism and the Subversion of Identity. Nova York: Routledge, 1990. No Brasil o livro foi publicado como Problemas de Gênero: Feminismo e Subversão da Identidade. (13a edição) Rio de Janeiro: Civilização Brasileira, 2017.
} 
Além disso, o inconsciente, sistema onde ocorrem e operam tais desdobramentos, é atemporal, significando que as perdas da primeira infância também são vividas como experiências não verbalizáveis de luto durante toda a vida, refinando ou estreitando os caminhos possíveis para o gênero.

Parece ser comum à visão de alguns autores da psicanálise (ver STOLLER, 2014) entender que o masculino necessita purgar o feminino para se fazer como tal.

Para Kimmel (1994), uma leitura mais psicanalítica da construção da identidade masculina sugere que tal esforço (no sentido de repudiar a mãe) como indicação de aquisição da identidade masculina, com três consequências para o garoto. Primeiro, ele afasta de si a verdadeira mãe, e com ela os traços de sustento, compreensão e ternura que ela possa ter personificado. Segundo, ele reprime em si próprio tais traços, pois eles revelam a separação incompleta da mãe. Terceiro, sua vida torna-se um eterno projeto para demonstrar que não possui nenhum dos traços da mãe. A identidade masculina nasce do não reconhecimento do feminino, não da afirmação direta do masculino, o que deixa a identidade masculina delicada e frágil (BENTO, 2012, p. 95-6).

Da nossa perspectiva entendemos que a internalização do objeto amado, em decorrência de sua possível perda, é uma estratégia de identificação que faz com que o sujeito masculino conserve traços do sujeito feminino em seu inconsciente, promovendo assim uma possibilidade emancipatória de encontrar outras performances de masculinidade, que não aquelas de cunho mais hegemônico.

Então, o gênero atualizado no constante devir do que significa ser sujeito é aquele orientado por estas identificações, mas não limitado por elas. Tais apontamentos sustentam que estamos falando de algo que não é o sexo biológico fundamentado em uma suposta relação com o natural.

Entendemos as relações que se estabelecem entre o sujeito-mundosujeito como mediadas. Isto significa que são semioticamente dadas, ou seja, sempre e somente realizáveis por meio de signos, assim constatamos que o natural como categoria direta e não mediada não existe.

É próprio do sujeito em toda sua complexidade realizar a busca incessante e inesgotável de si mesmo nas diversas e constantes camadas de mediação que o constituem. Isto nos leva a crer que o gênero é, em certa medida, um signo que não se esgota e que distanciado do "natural" finca suas âncoras no cultural, porém também derivando das internalizações 
realizadas pelo sujeito quando perde, ou vivencia fantasiosamente a perda do seu objeto amado.

Por isso mesmo, o peso do sujeito histórico é enorme nas condições performativas do gênero, haja visto, que inúmeras possibilidades de ser, como as decorrentes da transexualidade, foram relegadas aos cantos sociais mais obscuros por não perpetuarem as manifestações estereotipadas do que significava ser homem ou mulher nas sociedades ocidentais.

Aliás, a sociedade heteronormativa sempre foi exemplar na marginalização de singularidades discordantes, ou que se faziam surgir nos interstícios dos padrões razoavelmente estanques sobre o que significava ser homem e mulher. Segundo Connell (apud BENTO, 2012) existiriam 3 grupos de masculinidades a partir da ideia de uma singularidade hegemônica, essas masculinidades seriam a 1) subordinada, 2) cúmplice e 3) marginalizada.

Connell fundamenta o conceito de hegemonia com base em Gramsci, cuja categoria é utilizada em sua análise das classes sociais. Porém, Connell atenta para o caráter volátil da hegemonia, já que os padrões de masculinidades variam localmente e historicamente. Entretanto, a masculinidade hegemônica tem como modelo de referência o patriarcado visto que no âmbito das relações de gênero vai se configurar como processo dominante dos homens e de subordinação das mulheres (SOUZA, 2009, p. 125).

Retomando a masculinidade marginalizada, preferimos enquadrar esta singularidade como masculinidade periférica, visto que a expressão - marginalizada - pode trazer conotações não pertinentes aos interstícios que estamos buscando evidenciar, conotações que estariam relacionadas a leitura de possíveis conflitos entre classes sociais, não que este também não seja um campo frutífero para as discussões de gênero.

Sendo assim, o masculino periférico configura um tipo de performance de gênero em nossa sociedade, que também diz respeito às pessoas em situação de rua, que motivadas por diversos fatores acabaram encontrando maneiras outras de atuar sobre a sociedade, a partir de gêneros não reconhecidos ou institucionalizados.

É evidente que a masculinidade periférica é uma singularidade diferenciada, e que por isso não se presta a centralização oriunda historicamente do discurso burguês. Ela é uma singularidade que não tem vínculo com o domínio físico (basta que relembremos a narrativa de 
Adam e a violência pela qual passou), muito menos pelo psicológico, pois são vários os moradores em situação de rua que possuem algum tipo de transtorno mental. Quanto ao espacial, o nomadismo ao qual são obrigados a recorrer caracteriza a errância como índice de sua singularidade, bem como o desenraizamento familiar seja por tragédia, perda, violência ou mesmo por sua falta de vínculo simbólico (CAIM, 2016, p. 279).

Apesar da evidência de várias possíveis singularidades do masculino, as comunicações voltadas ao consumo insistem no vínculo de suas representações ao ideal de masculinidade hegemônica, no sentido de condicionada aos padrões patriarcais.

Entretanto, sejamos justos, no campo do consumo há marcas que estão assumindo valores e posições diferenciadas, por exemplo, como Doritos, Facebook e Google com seu apoio a causa LGBT, ou mesmo a C\&A com a promoção de uma moda genderless ${ }^{2}$, mais igualitária e menos divisionista. Outras marcas de moda caminham pelo ageless ${ }^{3}$ incitando seus consumidores a entenderem que moda não tem idade, $o$ que em termos de mercado é uma forma de ampliar seus consumidores.

\section{Comunicação, Consumo e Gênero}

A comunicação voltada para o consumo sempre foi pouco complexa e bastante restritiva, já que incapaz de refletir as multiplicidades de gêneros (que sempre existiram), posicionava-se a partir de uma relação bastante conciliatória com o status quo das aparências masculinas e femininas.

No entanto, a partir da década de 70 (lembrando que o movimento feminista explodiu na década de 60 e, também, estamos falando da onda hippie), no que tange ao masculino, podemos notar certo encaminhamento de novas formas de se pensar essa aparência, que tentavam captar algumas nuances presentes na sociedade brasileira. Obviamente, essas formas são devedoras dos grandes questionamentos surgidos com o movimento feminista (SOUZA, 2009), movimento estudantil, movimento hippie, que possibilitaram ao masculino um olhar diferenciado para si mesmo.

É da década de 70 em diante que surgem personagens como Garoto Bombril, Fernandinho das Camisas US Top, o Baixinho da Kaiser, o

\footnotetext{
2 Tradução nossa - genderless - sem gênero.

3 Tradução nossa - ageless - sem idade.
} 
Bonachão do Bamerindus, Sebastian da C\&A (MARCONDES, 2001) - que traziam traços distintos do estereótipo do machão extremamente valorizado pela publicidade da marca de cigarros Marlboro a partir da década de 50 e pelas telenovelas brasileiras.

Nitidamente, carregados de bom humor essas personagens da propaganda brasileira por tratar de assuntos como moda, cerveja, finanças, produtos para casa transformaram a linguagem publicitária de algo sisuda para uma abordagem mais suave, menos informativa e que valorizava muito mais a empatia com o consumidor. Não é preciso dizer que tais personagens tinham uma alta aceitação pelo público feminino.

Figura 01: Dilma e José Serra (GBB)

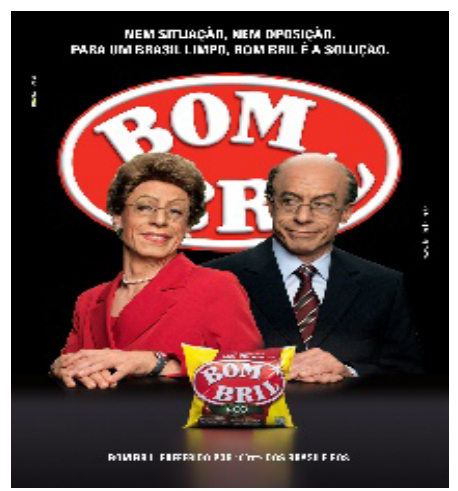

Fonte: o autor (2017)

Figura 03: Baixinho da Kaiser

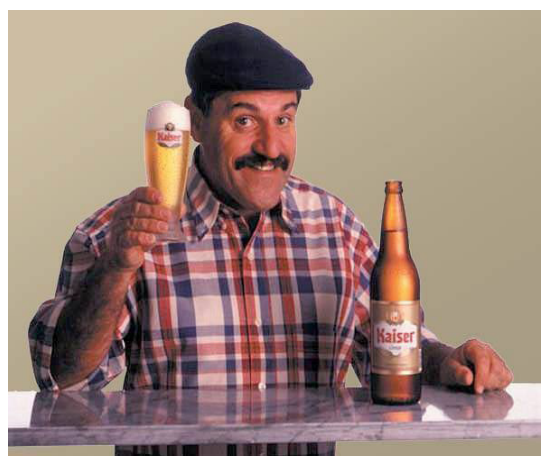

Fonte: o autor (2017)
Figura 02: Fernandinho

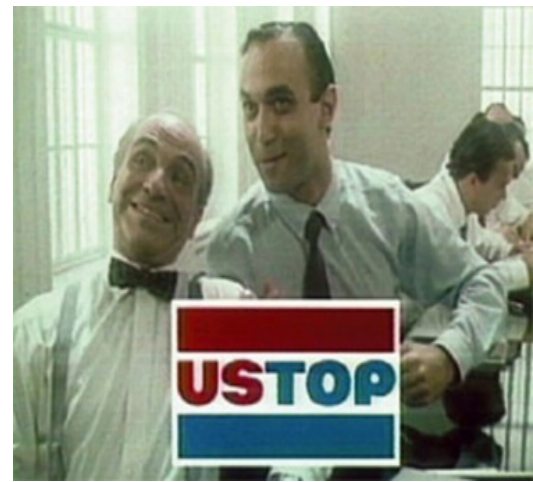

Fonte: o autor (2017)

Figura 04: Bonachão da Bamerindus

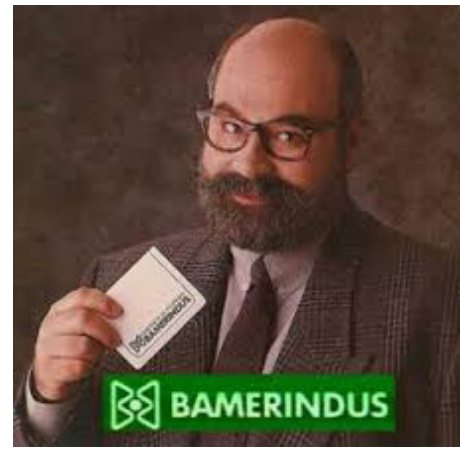

Fonte: o autor (2017) 
Figura 05: Sebastian

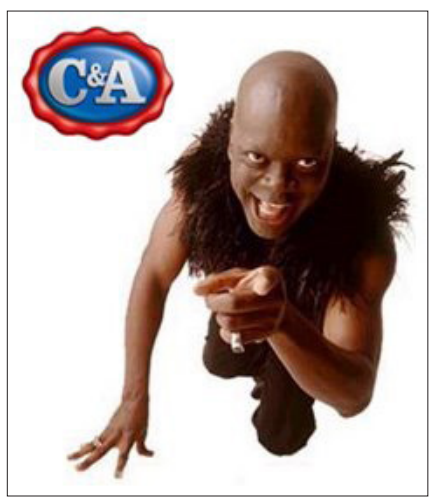

Fonte: o autor (2017)
Figura 06: Homem Marlboro

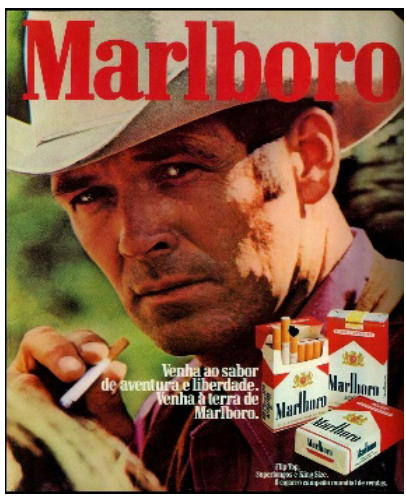

Fonte: o autor (2017)

O Homem de Marlboro surgiu para enfrentar um problema de marketing. Em 1954, uma delegação da Philip Morris se reuniu com Leo Burnett para explicar que a companhia queria mudar a imagem do cigarro Marlboro com filtro, considerado uma marca feminina. A companhia também estava entusiasmada com a nova embalagem flip-top que tinha inventado. No fim, Leo mudou a embalagem e reposicionou a marca. Além de criar uma nova imagem vigorosa para a marca, Leo também deu ao lettering de Marlboro um "M" maiúsculo e mudou a cor: as faixas vermelhas e brancas deram lugar a um sólido vermelho. Escreveu aos executivos da Philip Morris: "O caubói é um símbolo quase universal de masculinidade admirada... Parece até que o doutor Freud está no nosso Conselho de Planejamento. Mas não está. Fomos guiados por pesquisas e um antiquado bom senso" (TUNGATE, 2009, p. 90-1).

O caubói de Marlboro inicialmente lançado no mercado norte-americano ganhou o mundo e comprovou a previsão de Leo Burnett de que este símbolo era "quase universal". Em verdade, a universalidade estava em alguns traços dessa masculinidade viril (lembremos que antes da década de 50 o mundo havia enfrentado duas grandes guerras, que mexerem enormemente com as estruturas sociais. Então, parece crível que essa personagem devolvia certa estabilidade aos invólucros sociais que tiveram suas bases estremecidas) que parecem ter ressoado com traços distintos em diversas sociedades. As alterações na marca e embalagem, também, aumentaram os sentidos de masculinidade, principalmente, ao incorporar o vermelho sólido ao conjunto de elementos marcários.

Esse comportamento heteronormativo representado pela persona- 
gem de Marlboro refletia um poderoso sistema de réplicas de gênero do sistema patriarcal, que intentava manter sua estabilidade após a I e II Guerras Mundiais. "A imitação exaustiva dos modelos normativos não garante a constituição de uma estrutura sólida, mas, ao contrário, resulta na formação de uma identidade gênero sempre instável" (SAMPAIO, GARCIA, 2010, p. 88).

Particularmente, o lançamento desta personagem foi feito para associar os cigarros com filtros ao público masculino, já que este item era visto como feminino, por suavizar o sabor e os gases inalados.

A apropriação deste forte símbolo da cultura norte-americana (exaustivamente usado no cinema hollywoodiano por meio de atores como: John Wayne, Clint Eastwood, Paul Newman, Robert Redford, Gene Hackman) pela marca Marlboro foi uma estratégia publicitária criativa que elevou as taxas de consumo do produto e tornou a marca conhecida mundialmente.

Entretanto, no contexto brasileiro as personagens supracitadas $(\mathrm{Ga}$ roto Bombril, Fernandinho, Sebastian, Bamerindus, Baixinho) apelaram para uma expressão mais diferenciada de gênero. Ainda que traços como virilidade fossem conservados, havia uma predisposição da linguagem publicitária em explorar outras potencialidades, talvez, com o intuito de gerar mais identificação, ou apenas como uma forma de amenizar a linguagem tornando-a cada vez mais entretenimento.

É o caso do Garoto Bombril (GBB), que a partir de 1978 assumiu um papel de enorme destaque na publicidade brasileira fazendo intervenções no próprio cotidiano da sociedade ao se travestir de diversas personalidades e outras personagens. Esse garoto-propaganda trouxe para a linguagem publicitária e, consequentemente, para a sociedade brasileira uma aproximação com a fluidez do que atualmente consideramos como gênero.

Os personagens/personalidades “imitados” pelo GBB são: Che Guevara; Ronaldinho (jogador de futebol); Monalisa; Gil Gomes; Hilda Furacão e o Noviço, interpretados respectivamente por Ana Paula Arósio e Rodrigo Santoro na minissérie da Rede Globo; Xuxa grávida; a família do GBB - pai, mãe, irmãos, esposa, filhos; Bill Clinton e Monica Lewinsky; Walter Mercado; Enéas; Tiazinha; Padre Marcelo; Itamar Franco; Globeleza - Valéria Valência; o Oscar (a estatueta); Mister M; o presidente Fernando Henrique e sua esposa D. Ruth; Feiticeira; Ivete Sangalo e Luciano Huck; Ratinho; Adriane Galisteu; Ronaldinho e Milene Rodrigues; Silvio Santos; João Gilberto; Sandy e Junior; Ana 
Maria Braga; Alexandre Pires; Popó (boxeador); Reginaldo Rossi (cantor); Alberto Roberto - personagem de Chico Anysio; Juliana e Matheo - interpretados por Ana Paula Arósio e Tiago Lacerda na novela Terra Nostra; Padre Quevedo; Rubinho Barrichello; Celso Pitta e Nicéa Pitta; Pedro Álvarez Cabral. (CAIM, 2002, p. 18).

Ao usar o humor como forma de argumento publicitário, foi permitido a personagem se travestir em diferentes outros demonstrando assim alguma característica do produto e da marca, porém, de maneira implícita valorizava a experiência do gênero como performance, isto é, como ficção. Consequentemente, questionava a suposta naturalização da masculinidade hegemônica.

Sebastian, primeiro garoto-propaganda da marca C\&A (1990) e o primeiro negro no Brasil a protagonizar esse tipo de estratégia trouxe questionamentos importantes ao gênero, especialmente, em relação à etnia. Como bailarino a personagem usava o mote da marca "Abuse e Use" para se fazer presente nos vídeos promocionais, associando sua imagem à de um grande vendedor. A abrangência nacional da marca e de suas comunicações deu visibilidade a um consumidor pouquíssimo retratado na publicidade, os afro-descendentes.

No entanto, a imagem de personagem alegre, dançarino, esguio, flexível parece apenas reforçar padrões presentes e estereotipados sobre o masculino negro.

Ao caminharmos para uma representação exploratória e hegemônica, sem grandes presunções de esgotar o assunto, da imagem do negro na publicidade no contexto brasileiro, podemos observar uma tipologia inicial, constituída de três tipos: os deuses de ébano, o negro como homem popular brasileiro e o negro no Brasil politicamente correto (TRINDADE, 2011, p. 175).

Usando as divisões definidas pelo autor podemos considerar que o Sebastian se encontra na segunda categoria: o negro como homem popular brasileiro. Vejamos o que o autor nos diz sobre:

O negro como homem popular transitaria entre duas representações principais: a do negro lúgubre, luxurioso, bem-humorado, associada à diversão, às manifestações populares da música (o samba, batuques), ao carnaval, ao futebol, e a do negro trabalhador, ocupando postos de trabalhos ligados às classes subalternas. Tratam-se de representações circunscritas, em nosso entendimento, aos modos de estereotipados 
hegemônicos de ver o negro na nossa sociedade, cuja explicações históricas foram discutidas em ampla literatura científica nacional (idem, 2011, p. 176).

Segundo o enquadramento proposto, Sebastian seria o protótipo do homem negro luxuoso, bem-humorado, divertido e associado à música e dança. Assim, apesar da conquista importante do espaço publicitário, que cedeu caminho a um protagonista negro para uma grande marca, de certa forma, suas representações validavam argumentos já presentes no imaginário brasileiro sobre o papel destinado a um homem negro.

Se por um lado podemos notar esse gênero como representativo do status quo, por outro não podemos nos esquivar a apontar a relevância do espaço conquistado por essa personagem, que deu visibilidade a consumidores e profissionais (como o Sebastian) esquecidos pela grande mídia.

Por fim, o Baixinho da Kaiser e o senhor bonachão do Bamerindus (banco comprado em 1997 pelo HSBC, que posteriormente foi comprado pelo Bradesco) apresentaram ao consumidor brasileiro outras possibilidades de gênero.

O baixinho era, de fato, uma personagem com estatura abaixo da média brasileira, ou seja, bem distante da imagem de galã ou do que se esperava de um garoto-propaganda, porém novamente trazia leveza e diversão à comunicação publicitária, na medida em que sempre se dava bem nas situações ficcionais construídas pela propaganda da marca.

O senhor bonachão do Bamerindus fez apontar na linguagem publicitária brasileira um homem de meia idade, com trejeitos e aparência de bom avô (farta barba grisalha), entretanto vestindo terno e gravata que lhe conferia seriedade e credibilidade.

Estas personagens, também, serviram para colocar em discussão alguns preceitos relativos à masculinidade hegemônica, como questões sobre sucesso, aparência, boa vida, poder entre outros fatores.

Desta forma, tendo sido preparado o terreno desde 1970 por diversos personagens e argumentos publicitários que se propunham a indicar a questão do masculino com mais leveza e bom-humor, chegamos agora à discussão sobre como a marca Natura Homem assumiu para si o embate de gênero ao questionar explicitamente a masculinidade hegemônica. 


\section{Natura Homem: vídeo-manifesto das masculinidades}

Alguns dados numéricos são relevantes para discutirmos o posicionamento da marca Natura no segmento de cosméticos masculino. De forma geral, em $2015^{4}$ o segmento faturou algo em torno de 42 milhões de dólares, sendo que desse total aproximadamente 21 milhões de dólares foram oriundos do consumo masculino. Ainda com base na mesma fonte, nos últimos 5 anos (2011-2016) esse segmento cresceu 16\% e é o segundo maior mercado mundial, ficando atrás somente do mercado norte-americano. Já os dados projetados para de 2017 espera-se aumentar em $4,5 \%$ o faturamento de cosméticos sobre o segmento masculino, sendo que em 2016 o crescimento foi aproximadamente de $4,6 \%{ }^{5}$.

As cifras impressionantes do setor nos fazem olhar com mais atenção para a discussão de gênero proposta pela marca Natura, em seu vídeo intitulado - A Natura homem celebra todas as maneiras de ser homem.

Sendo assim, transpomos abaixo alguns frames do vídeo seguido pela transcrição do áudio.

Figura 07: Frame do vídeo A Natura homem celebra todasas maneiras de ser homem

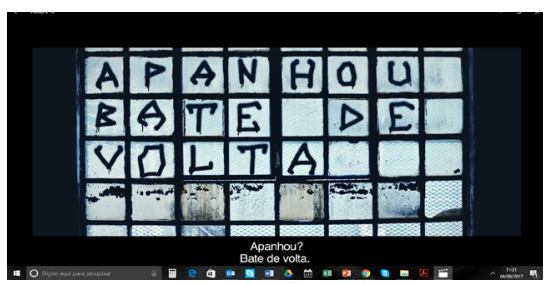

Fonte: o autor (2017)

Figura 09: Frame do vídeo A Natura homem celebra todas as maneiras de ser homem

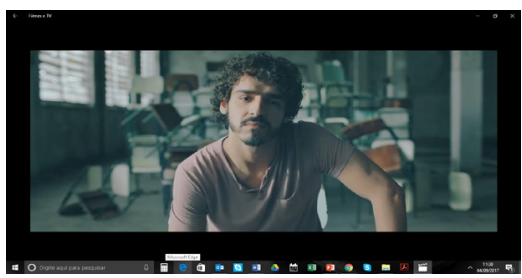

Fonte: o autor (2017)
Figura 08: Frame do vídeo A Natura homem celebra todas as maneiras de ser homem

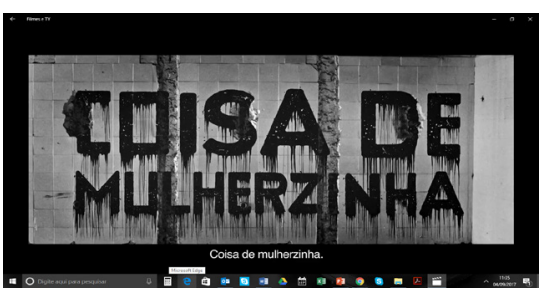

Fonte: o autor (2017)

Figura 10: Frame do vídeo A Natura homem celebra todas as maneiras de ser homem

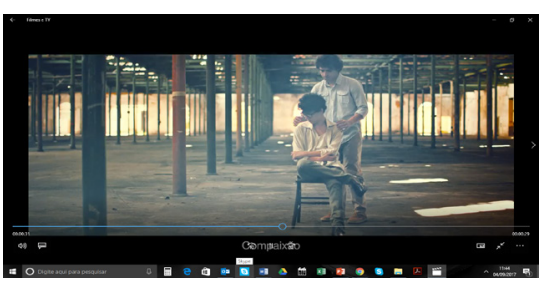

Fonte: o autor (2017) 
Figura 11: Frame do vídeo A Natura homem celebra todas as maneiras de ser homem

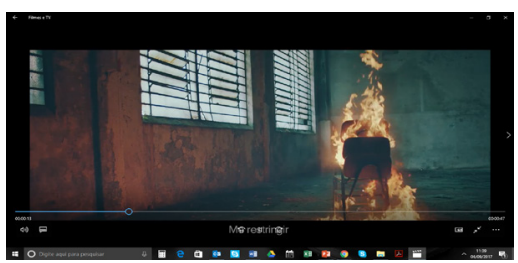

Fonte: o autor (2017)

Figura 13: Frame do vídeo A Natura homem celebra todas as maneiras de ser homem

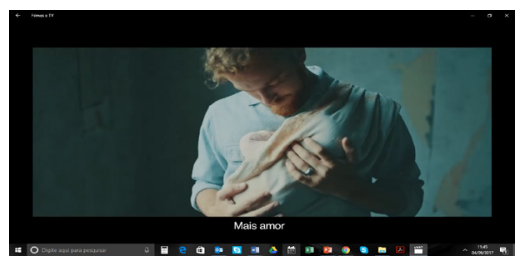

Fonte: o autor (2017)
Figura 12: Frame do vídeo A Natura homem celebra todas as maneiras de ser homem

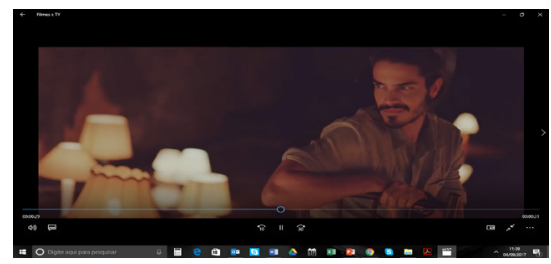

Fonte: o autor (2017)

Figura 14: Frame do vídeo A Natura homem celebra todas as maneiras de ser homem

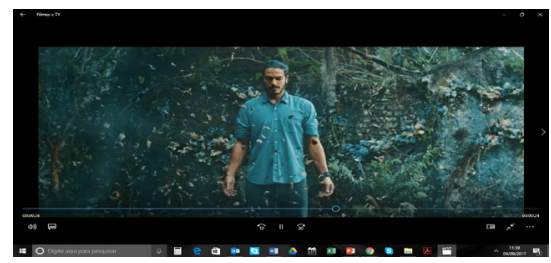

Fonte: o autor (2017)

Figura 15: Frame do vídeo A Natura homem celebra todas as maneiras de ser homem

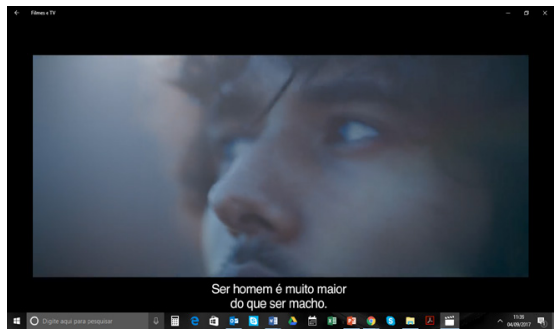

Fonte: o autor (2017) 
Segue a transcrição da locução em off do vídeo.

Homem não chora. Apanhou? Bate de volta. Sensível, afetivo é coisa de mulherzinha. Você não vai me constranger, me restringir, me reduzir, me amarrar, me retalhar. Você não vai amordaçar meu coração, minha emoção, minha expressão. Sou homem, sou pele, sou nervos, sentimento, paixão, compaixão, ação, respiração, amor, mais amor, conciliador. Celebro minha flexibilidade, verdade, sinceridade. Hetero, homo, trans, amanhãs, atitude, completude, inteiro, guerreiro. Ser homem é muito maior que ser macho. Natura Homem celebra todas as maneiras de ser homem (Natura Homem, 2017).

O texto inicia de maneira didática opondo situações conflitantes "homem x choro", "apanhar x bater", "sensibilidade X universo masculino", "masculino x feminino". Fenomenologicamente, a narrativa abusa da secundidade como forma de criar choque, como maneira explícita de chamar a atenção, para depois conduzir a audiência para um universo de maior complexidade, reino da terceiridade: "Celebro minha flexibilidade, verdade, sinceridade. Hetero, homo, trans, amanhãs, atitude, completude, inteiro, guerreiro".

O manifesto Natura para sua linha de produtos voltada para o consumidor masculino já irrompe no momento da secundidade, que é o momento fenomenológico onde as situações binárias acontecem, onde os choques ocorrem, onde se dá a ação e reação. É o momento da surpresa que atrai a atenção, capta a audiência para o signo veiculado, funcionando a partir da estratégia de sedução (SANTAELLA, 2010).

Inteligentemente construído o texto abusa de elementos clichê colocados em rota de colisão com seus opostos. Como expressado anteriormente, é por meio do choque que a atenção da audiência é captada, já que é próprio dos índices ali dispostos estabelecerem relações factuais com seus objetos, que podemos pressupor como sendo as próprias convenções sociais as quais todos os sujeitos de singularidades masculinas estão expostos.

A afirmativa "Você não vai me constranger, me restringir, me reduzir, me amarrar, me retalhar" se oferece como diálogo onde o interlocutor é um existente e uma indicação - você - todavia, tão geral ao ponto de ser todo mundo. Aqui há uma clara intenção de transformar metaforicamente esse pronome demonstrativo (portanto índice) em uma alusão a toda a sociedade.

$\mathrm{O}$ "você" dito pela personagem de forma sincera indicializa a pró- 
pria audiência, pois o modelo olha para a câmera. De maneira ousada, a marca "briga" com sua audiência, finca seu valor e alicerça seu posicionamento, independentemente, se o próprio consumidor tiver suas dúvidas em relação ao que está sendo manifestado. Todavia, acreditamos que seria mais apropriado entender esse pronome demonstrativo como indicializando a sociedade e suas convenções, já que a locução em off inicia colocando em xeque tais crenças.

Após esses embates o intérprete é colocado em questionamento, já que o texto o encaminha para uma discussão de gênero. A assertiva "Ser homem é muito maior que ser macho" posiciona a marca a partir da leitura da masculinidade como performance, que se distancia do biológico e do supostamente natural. Desta maneira, se a própria masculinidade é uma performance isso significa que alguns dos seus traços também são escolhas, já que o agir no mundo, por mais que seja orientado por mecanismos inconscientes, é também uma atividade consciente.

A celebração de todas as formas de ser homem expande o mercado da marca. Resgatando o que foi afirmado no início deste trabalho, o gênero sempre foi usado como uma maneira de dividir o mercado entre homem e mulher - existem produtos para homens e existem produtos para mulheres, alguns podem ser para os dois, mas isto não pode e não deve ser a regra.

O que a Natura faz é justamente ampliar o leque de consumidores afirmando que sua marca é para todos os tipos de homens, isto significando que todos os homens são bem-vindos a consumi-la e não, necessariamente, só a linha Natura Homem.

No que tange à narrativa imagética o vídeo-manifesto abusa de locações inusitadas e conceituais, entretanto, há um elemento comum que identificamos que é o isolamento. Apenas em um dos frames - compaixão - é que vemos dois homens interagindo, nos demais todos estão sozinhos. Mesmo no frame - mais amor - em que o homem aparece supostamente segurando um bebê, a sensação é de isolamento, porque a criança não aparece.

A compaixão é palavra que quando decomposta apresenta 3 sílabas da seguinte forma: com / pai / xão. As interpretações a partir desta divisão são ricas, já que remetem a uma relação onde há paixão, ou mesmo uma situação onde é com o pai que se estabelece a relação mais firme, mais próxima do chão (xão - chão = homófonas).

No frame da palavra - compaixão - a imagem é de um homem sentado e outro em pé atrás dele colocando suas mãos no ombro do 
que está abaixo. A relação não apenas remete a compaixão, como são possíveis outras associações por semelhanças, como as relações entre pais e filhos, onde o sentido de autoridade é tomado por aquele que está de pé, subordinando o que está sentado, além da imagem de um casal homo ou mesmo de amigos em uma relação afetiva mais próxima, o que é justamente a proposta da marca: incentivar masculinidades que não caminhem exclusivamente pela masculinidade hegemônica, como única forma possível de ser.

Todavia, ainda que tenha realizado um lindo manifesto a marca incorre no mesmo argumento patriarcal, o de que a masculinidade é uma construção isolada, medida e desenvolvida com base na força do sujeito em si, sem que suas relações sejam de fato explicitadas. $\mathrm{O}$ isolamento de todas as personagens do vídeo é sintomático de uma masculinidade ainda muito enraizada e difícil de ser deixada para trás, encaminhada por questões heteronormativas, portanto, alicerçada no sistema patriarcal.

\section{Considerações Finais}

O rompimento com a masculinidade hegemônica é uma atividade difícil de ser realizada, ainda mais quando tomamos como objeto de estudos as comunicações publicitárias, pois que também devemos entendê-las a partir de uma lógica consubstanciada pelo mercado, onde prevalecem representações padrões já que são menos invasivas ou tendo menor chance de serem questionadas social e culturalmente pelas diversas camadas de consumidores, o que em última instância significa não perder investimentos feitos nas comunicações das marcas, ou mesmo perder vendas.

Ainda assim, notamos que há um movimento interessante partindo de algumas marcas que estão assumindo causas relacionadas ao gênero, como àquelas que se posicionam a favor dos direitos LGBT entre outros anseios presentes em nossa sociedade, como a igualdade de gêneros, a liberdade de gêneros etc.

No tocante a nossa pesquisa, entendemos que a masculinidade dita hegemônica ainda é o lugar de excelência de onde são pensadas as diversas aparências do masculino. Fonte dominante de singularidades, ela se estabelece como grande alicerce do gênero masculino, inclusive, esmagando essa discussão e a transformando em "ideologia do gênero", imputando a esse campo um viés doutrinário, na medida em que o as- 
socia politicamente aos recursos ideológicos e conceituais da esquerda e, portanto, destruidor dos "bons e velhos costumes".

Ainda que o objetivo deste trabalho não seja uma discussão política é inegável que o gênero como performance também passa por essa área, já que o corpo como recurso histórico sempre foi controlado e orientado de acordo com as visões predominantes de mundo de cada sociedade o que significa um olhar político.

No entanto, o tema principal deste trabalho é demonstrar como singularidades diferenciadas do masculino estão escapando pelos interstícios das performances conservadoras e se fazendo presentes nos discursos publicitários de várias marcas. Exatamente por isso optamos pela análise mais detalhada do vídeo-manifesto da marca Natura Homem.

O vídeo estabelece um discurso nitidamente focado nas questões de gênero, em especial, aquelas que envolvem o masculino e suas possibilidades de performance na sociedade. Claro que devemos lembrar que esse vídeo só foi possível de ser realizado e veiculado, porque anteriormente algumas personagens publicitárias povoaram o imaginário dos consumidores com dicentes (no sentido dado pela semiótica), ou melhor, com interpretantes que antecipavam tais questionamentos.

A partir de nossa leitura podemos concluir que a linguagem publicitária e, por consequência, os consumidores foram sendo preparados para receber interpretantes mais sérios e profundos, pelo motivo das construções publicitárias terem colocado pequenas pílulas da relevância do gênero na semiosfera. Se o tema era antigamente exposto como mero entretenimento - Garoto Bombril e Sebastian - com o vídeo-manifesto da Natura Homem ele encontrou a relevância certa dentro das possibilidades lógicas da publicidade, isto é, dentro de sua efemeridade e capacidade de refletir a realidade sócio cultural do momento de uma maneira mais suave.

É certo que estamos vendo apenas um movimento de um processo iniciado - dentro da linguagem publicitária - na década de 70 , porém devedor das turbulências provocadas na década de 60 pelo movimento feminista e outros, sendo assim, pouco ainda temos de material para entender, de fato, quais serão as mudanças provocadas por essas novas representações, ou melhor, por essas diferentes singularidades do masculino que se estão dando a ver. 


\section{REFERÊNCIAS}

ALMEIDA, Hamilton. Perspectivas 2017 - Cosméticos: inovação e diversificação de produtos estimulam vendas no país e também no exterior. Cosméticos: Química.com, 07 de março de 2017. Disponível em: <https://www.quimica.com.br/perspectivas-2017-cosmeticos-inovacao-e-diversificacao-de-produtos-estimulam-vendas-no -pais-e-tambem-no-exterior/>. Acesso em 26/07/2017.

BENTO, Berenice. Homem não tece a dor: queixas e perplexidades masculinas. Natal, RN: EDUFRN, 2012.

BUTLER, Judith. Problemas de Gênero: feminismo e subversão da identidade. $13^{\mathrm{a}}$ ed. Rio de Janeiro: Civilização Brasileira, 2017.

CAIM, Fábio. São Paulo Invisível e as singularidades do masculino: representações do masculino periférico na maior mídia social do mundo, o facebook. In: CHIACHIRI, Roberto, PERSICHETTI, Simoneta (organizadores). Imagem e Inserção Social II. São Paulo: Uni, 2016, p. 265-282.

CAIM, Fábio. Singularidades do Masculino na Publicidade Impressa: semiótica e psicanálise. São Paulo: Intermeios, 2011.

CAIM, Fábio (Fábio Caim Viana). Garoto Bombril: semiose da identidade midiática. 2002. 72f. Dissertação (mestrado em Comunicação e Mercado) - Faculdade Cásper Líbero. São Paulo, 2002.

CONNELL, Raewyn; PEARSE, Rebecca. Gênero: uma perspectiva global - compreendendo o gênero - da esfera pessoal à política - no mundo contemporâneo. São Paulo: Versos, 2015.

DINO. Segundo ABIHPEC: cosméticos masculinos representam mais de $\mathbf{R} \mathbf{2 1}$ milhões do faturamento do setor. São Paulo: Revista Exame.com. Disponível em: $<$ http://exame.abril.com.br/negocios/dino/segundo-abihpec-cosmeticos-masculinos -representam-mais-de-r21-milhoes-do-faturamento-no-setor-shtml/>. Acesso em 26/07/2017.

GIL, Camila; CAMPOMAR, Marcos Cortez. Analisando VALS como instrumento de segmentação. São Paulo: USP, IX SemeAD, agosto de 2006. Disponível em: $<$ http://sistema.semead.com.br/9semead/resultado_semead/trabalhosPDF/178.pdf>. Acesso em 26/07/2017.

MARCONDES, Pyr. Uma história da Propaganda Brasileira: melhores campanhas, grandes gênios da criação, personagens inesquecíveis. Rio de Janeiro: Ediouro, 2001.

RAMOS, Ricardo. Do reclame à comunicação: pequena história da propaganda no Brasil. São Paulo: Atual, 1985. 
SALIH, Sara. Judit Butler e a Teoria Queer. Belo Horizonte: Autêntica, 2013.

SAMPAIO, Ronaldo Sousa; GARCIA, Claudia Amorim. Dissecando a masculinidade na encruzilhada entre a psicanálise e os estudos de gênero. Psicologia em Revista, PUCMinas, v. 16, n.1, p. 81-102, abr. 2010. Disponível em: <http://periodicos.pucminas.br/index.php/psicologiaemrevista/article/view/P.1678-9563.2010v16n1p81>. Acesso em 27/07/2017.

SANTAELLA, Lucia; NÖTH, Winfried. Estratégias semióticas da publicidade. São Paulo: Cengage Learning, 2010.

SCALLA, Luana. Como nasceu Sebastian, o $1^{\circ}$ garoto-propaganda negro do país. São Paulo: Revista Exame.com. Disponível em: <http://exame.abril.com.br/marketing/como-nasceu-sebastian-o-1o-garoto-propaganda-negro-do-pais/. Acessado em 27/07/2017>.

SIMÕES, Roberto. A Propaganda no Brasil: evolução histórica. São Paulo: ESPM, Referência, 2006.

SOUZA, Márcio Ferreira. As análises de Gênero e a formação do campo de estudos sobre a(s) masculinidade(s). Mediações Revista de Ciências Sociais. UEL, v. 14, n.2, p. 123-144, Jul/Dez. 2009. Disponível em: file://C:/Users/F\%C3\%A1bio\%20Caim/ Downloads/4510-15528-1-PB.pdf. Acesso 26/07/2017. Acesso em 27/07/2017.

STOLLER, Robert. Perversão: a forma erótica do ódio. $1^{\text {a }}$ ed. 1975. São Paulo, Brasil: Editora Hedra, 2014.

TUNGATE, Mark. A História da Propaganda Mundial. São Paulo: Cultrix, 2009.

TRINDADE, Eneus. Perspectivas dos usos e consumos da imagem do negro na publicidade contemporânea brasileira. In: BATISTA, Leandro Leonardo, LEITE, Francisco (organizadores). O negro nos espaços publicitários brasileiros: perspectivas contemporâneas em diálogo. São Paulo: Escola de Comunicação e Artes/USP: Coordenadoria dos Assuntos da População Negra, 2011, p. 173-186.

VÍDEO NATURA. A linha Natura Homem celebra todas as maneiras de ser homem. Canal Natura Brasil: Youtube. Disponível em: <https://www.youtube.com/ watch?v=W5SAmO6ZzF8. Acessado em 26/07/2017>. 